\title{
Finite element simulation of delamination process in composite materials
}

\author{
Emilia Sabău ${ }^{1, *}$, Cristian Vilău ${ }^{2}$, Paul Bere $^{1}$ and Adrian Popescu ${ }^{1}$ \\ ${ }^{1}$ Technical University of Cluj-Napoca, Manufacturing Engineering Department, 103-105 Muncii Bvd. \\ Cluj-Napoca, Romania \\ ${ }^{2}$ Technical University of Cluj-Napoca, Mechanical Engineering Department, 103-105 Muncii Bvd. \\ Cluj-Napoca, Romania
}

\begin{abstract}
The delamination phenomenon is undesirable and constitutes a major problem. In this paper, a study of delamination for composite materials reinforced with unidirectional glass fibers in polyester matrix is analyzed. The composite plates were made using two manufacturing technologies, hand lay-up and compression hand lay-up process. The study found out the maximum value of the force where delamination occurs and the specific delamination resistance. Also, it's done a finite element simulation of delamination process at polymeric composite materials under transverse loads. The propagation model of delamination was implemented in finite element ANSYS software. There are presented the used materials for samples, the manufacturing process, laboratory equipment and the experimental results.
\end{abstract}

\section{Introduction}

Composite materials are made of reinforcing and matrix materials having strength characteristics. The interface between the materials plays an essential role in the mechanical behavior. Impact, shocks, loadings or repeated cyclic stresses can cause the laminate to separate, forming a structure of separate layers, with significant loss of mechanical strength, a condition known as delamination, [1].

Delamination is interlaminar damage and can be produced during production or exploitation of the composite structure. It is an insidious failure that's develops inside of the material, without being obvious on the surface. The core of the material is opaque, that's why it is difficult to evaluate the contact that was realized between the material layers during the manufacturing process, [2-4].

Finite element analysis (FEA) is a numerical solution for solving problems that can be expressed in mathematical language. The FEA formulation of the problem results in a system of partial derivative equations. [5-8]. Some researchers were done simulations of delamination propagation in composite laminates with the help of finite element analyses.

* Corresponding author: emilia.sabau@tcm.utcluj.ro 
A finite element for modeling delamination in a composite beam has been developed by [9]. The delaminated beam is divided into two sublaminates, above and below of the delamination plane, and modeled with finite elements.

A.M. Elmarakbi et. al. [10], study the delamination growth under transverse loads in laminated composite materials using finite element method.

Some researchers developed a model for delamination propagation in laminated composites to permit the prediction of degradation in materials due to delamination process [11]. To simulate the 3-point bending test the ABAQUS software was used.

Also, S. Huzni et. al. [12] used the finite element software ABAQUS to provide the cohesive elements for studying the delamination process in composite laminates.

Interface elements and an interface damage law was used by [13] in finite element analysis of delamination for laminated composites.

A.M. Girao et. al. [14] show that the physical mechanisms can be accurately represented through finite element method, such as delamination, laminate inplane failure and behavior at notches.

A failure criterion and damage properties are investigated to model delaminations in composite parts by [15]. These presents a simulation of failures in laminated composite materials.

Taking into consideration the previous researches in the field, the purpose of this study was to evaluate the delamination process for composite materials reinforced with unidirectional glass fibers in polyester matrix. A study on the delamination testing was done. The analysis found out the maximum value of the force where delamination occurs. There, also a finite element analysis of delamination for unidirectional composites was presented.

\section{Materials and method}

The strength of laminated fiber reinforced composite materials depends on the combination of the layers orientations.

The used materials for the composite plates were unsaturated polyester resin (Lerpol TIX 3603/R) as matrix and for reinforced fiber glass materials (unidirectional fabric 225 $\mathrm{g} / \mathrm{m}^{2}$ ). They were obtained by hand lay-up process and compression hand lay-up process. The hand lay-up technology is the most used manufacturing process for the composite material parts.

In order to show the pressure influence on mechanical properties at delamination tests, a pressure of $0,16 \mathrm{MPa}$ was applying, on unidirectional composite plates made by compression hand lay-up process. After the layers of the composite have been obtained, before polymerization, the mold was compressed with a power-press, in order to homogenize the structure and to remove the surplus of the resin. The mold consists of two metal plates with dimensions of $300 \times 300 \mathrm{~mm}$. The manufacturing process was performed at ambient temperature of $20{ }^{\circ} \mathrm{C}$.

The experimental tests at delamination were done according to ASTM D 5528-01 [16], schematically represented in figure 1.

The samples were cut from the obtained plates where the fiber orientation in the samples was at $0^{\circ}$. During the manufacturing process, at one end of the plate was inserted a polypropylene thin film of $50 \mu \mathrm{m}$ with length $\mathrm{a}=63 \mathrm{~mm}$. It was considered that the number of layers to be equal to the one side and other of the film. 


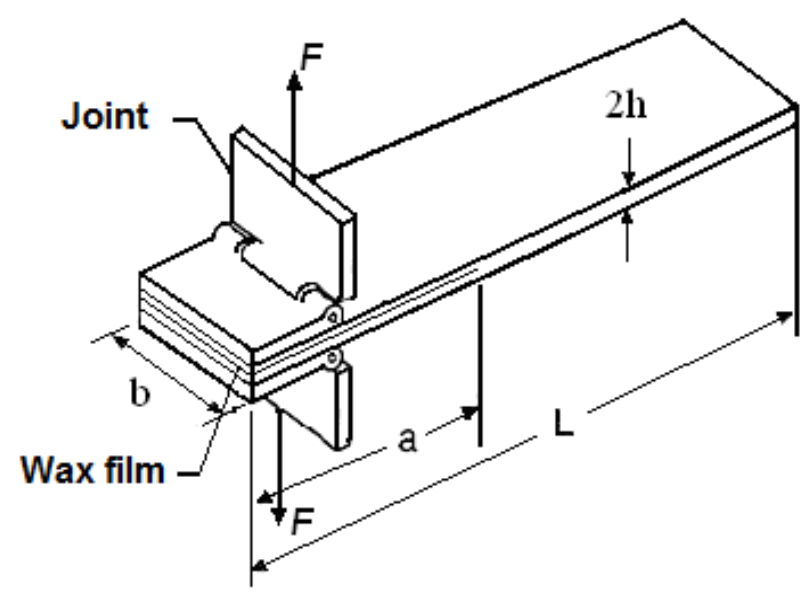

Fig. 1. Sample for delamination test.

The samples have 12 layers and were cut from the composite plates using a diamond disc at $25 \times 3 \times 125 \mathrm{~mm}$ dimensions. At the end of the samples, where the film has been inserted, two steel metal profiles by $25 \times 25 \mathrm{~mm}$ were glued, to be fixed it in the tensile test machine grips. There were used hinge formed from two-piece articulated on an axle, to remove any undesirable additional stresses which may occur during the sample tests.

\section{Experimental researches}

The delamination tests of the samples were performed on the universal testing machine type Zwick/Roell Z150, equipped with a process computer having the possibility to draw variation diagrams of force during application, Figure 2 . Test speed was of $2 \mathrm{~mm} / \mathrm{min}$.

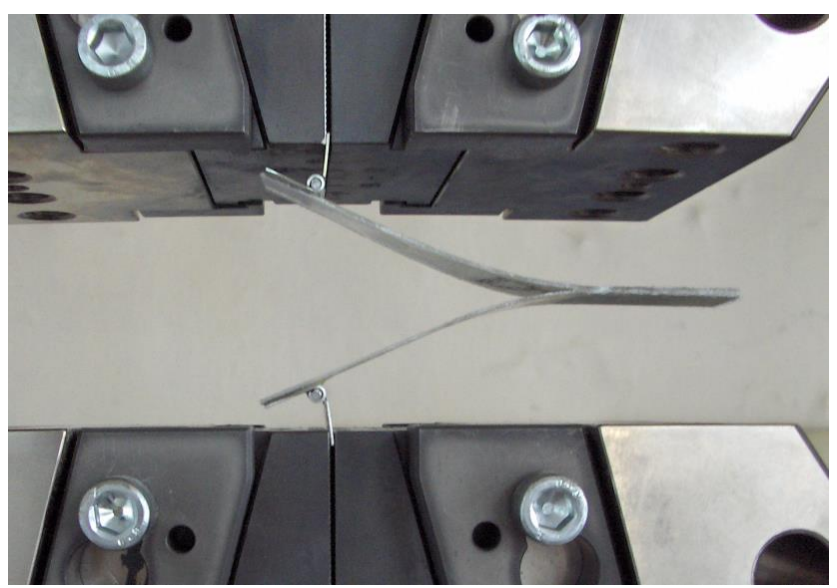

Fig. 2. Delamination test.

To determine the specific resistance at delamination $\left(\sigma_{\mathrm{d}}\right)$ has been reported the maximum force at sectional aria required, using the relation:

$$
\sigma_{\mathrm{d}}=\frac{F_{\max }}{b}[\mathrm{~N} / \mathrm{mm}]
$$


where: $F_{\max }-$ maximum force necessary to cause delamination between the sample layers, $[\mathrm{N}] ; b$ - sample width, [mm].

The results of the maximum force $F$ at delamination tests, corresponding to the displacement and delamination resistance for the both manufacturing process of unidirectional fiber composite plates, are presented in table 1.

Table 1. Experimental results at delamination tests

\begin{tabular}{|c|c|c|c|}
\hline $\begin{array}{l}\text { Manufacturing } \\
\text { process }\end{array}$ & $\begin{array}{l}\text { Maximum force } \\
\qquad \mathrm{F}[\mathrm{N}]\end{array}$ & $\begin{array}{c}\text { Average maximum } \\
\text { force } \\
\mathrm{F}_{\max } \operatorname{med}[\mathrm{N}] \\
\end{array}$ & $\begin{array}{c}\text { Average specific } \\
\text { resistance } \\
\sigma_{\mathrm{d} \text { med }}[\mathrm{N} / \mathrm{mm}] \\
\end{array}$ \\
\hline \multirow{5}{*}{ Hand lay-up } & 52,5 & \multirow{5}{*}{50,31} & \multirow{5}{*}{2,01} \\
\hline & 54,5 & & \\
\hline & 44,05 & & \\
\hline & 49,2 & & \\
\hline & 51,32 & & \\
\hline \multirow{5}{*}{$\begin{array}{l}\text { Compression hand } \\
\text { lay-up at } 0,16 \mathrm{MPa}\end{array}$} & 29 & \multirow{5}{*}{30,92} & \multirow{5}{*}{1,24} \\
\hline & 31 & & \\
\hline & 31,5 & & \\
\hline & 30,8 & & \\
\hline & 32,3 & & \\
\hline
\end{tabular}

By compression hand lay-up process, a 38,54 \% less force value at delamination was obtained than in the case of the simple hand lay-up process, due to phenomena that occur at the interface between fibre and matrix and resin variation volume. The important role is played by the matrix, the force at delamination being taken by the resin.

\section{Finite element analyses of delamination}

For this research the ANSYS 16.0 Software was used. The proposed objective was to analyze and to determine the force at delamination for unidirectional fiber glass polyester composites samples during the experimental tests.

Figure $3 \mathrm{a}$. shows the mesh distribution in the samples where the mesh size was $0,2 \mathrm{~mm}$. In this simulation case, a mesh with 21959 nodes and 14413 elements has been generated. The mesh density in the area of crack initiation, presented in Figure $3 \mathrm{~b}$., was $0,05 \mathrm{~mm}$.

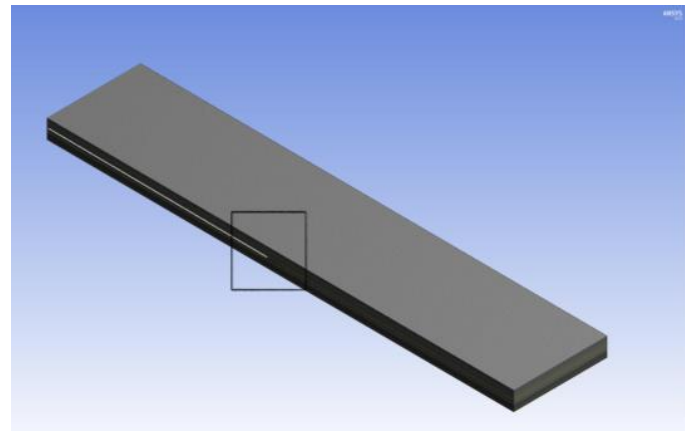

a.

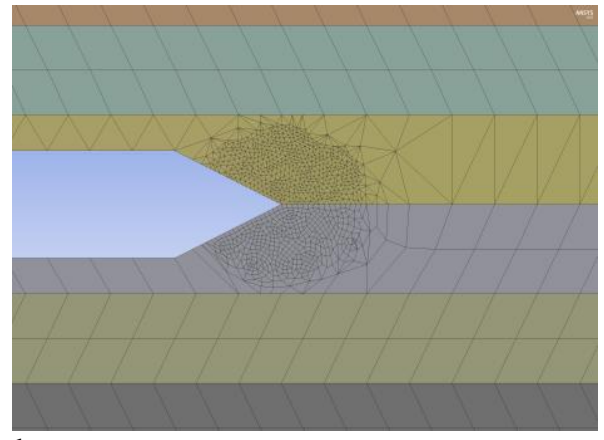

b.

Fig. 3. a. Finite element network. b. Detail of the mesh density in the area of crack initiation.

Like boundary conditions, the end of the right side of the sample is rigid fixed, and the left side has imposed displacements on both sides of the sample. 
Figure 4 shows the force values at delamination obtained during the finite element simulation. The maximum force at delamination was $316,24 \mathrm{MPa}(51,738 \mathrm{~N})$.

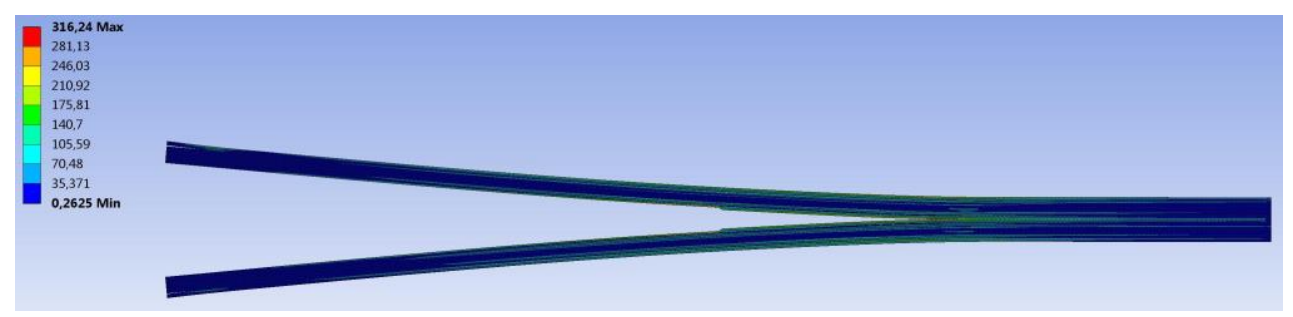

Fig. 4. Finite element simulation at delamination.

In Table 2 are presented the results of force reaction at delamination vs. time during the finite element simulation. Also, these results are show in the diagram from Figure 5.

Table 2. Delamination values of force reaction vs. time

\begin{tabular}{|c|l|l|l|l|l|l|l|l|l|l|}
\hline $\begin{array}{c}\text { Time } \\
{[\mathrm{s}]}\end{array}$ & 0,1 & 0,2 & 0,3 & 0,4 & 0,5 & 0,6 & 0,7 & 0,8 & 0,9 & 1,0 \\
\hline $\begin{array}{c}\text { Force } \\
{[\mathrm{N}]}\end{array}$ & 6,9385 & 13,875 & 20,439 & 26,373 & 31,622 & 36,159 & 40,18 & 43,443 & 46,16 & 48,2 \\
\hline
\end{tabular}

\begin{tabular}{|c|l|l|l|l|l|l|l|l|l|l|}
\hline $\begin{array}{c}\text { Time } \\
{[\mathrm{s}]}\end{array}$ & 1,1 & 1,2 & 1,3 & 1,4 & 1,5 & 1,6 & 1,7 & 1,8 & 1,9 & 2,0 \\
\hline $\begin{array}{c}\text { Force[ } \\
\mathrm{N}]\end{array}$ & $\begin{array}{l}49,81 \\
3\end{array}$ & $\begin{array}{l}50,8 \\
9\end{array}$ & $\begin{array}{l}51,58 \\
6\end{array}$ & $\begin{array}{l}51,73 \\
8\end{array}$ & $\begin{array}{l}51,67 \\
4\end{array}$ & $\begin{array}{l}51,31 \\
5\end{array}$ & $\begin{array}{l}50,78 \\
3\end{array}$ & $\begin{array}{l}50,01 \\
3\end{array}$ & $\begin{array}{l}49,11 \\
4\end{array}$ & $\begin{array}{l}48,15 \\
2\end{array}$ \\
\hline
\end{tabular}

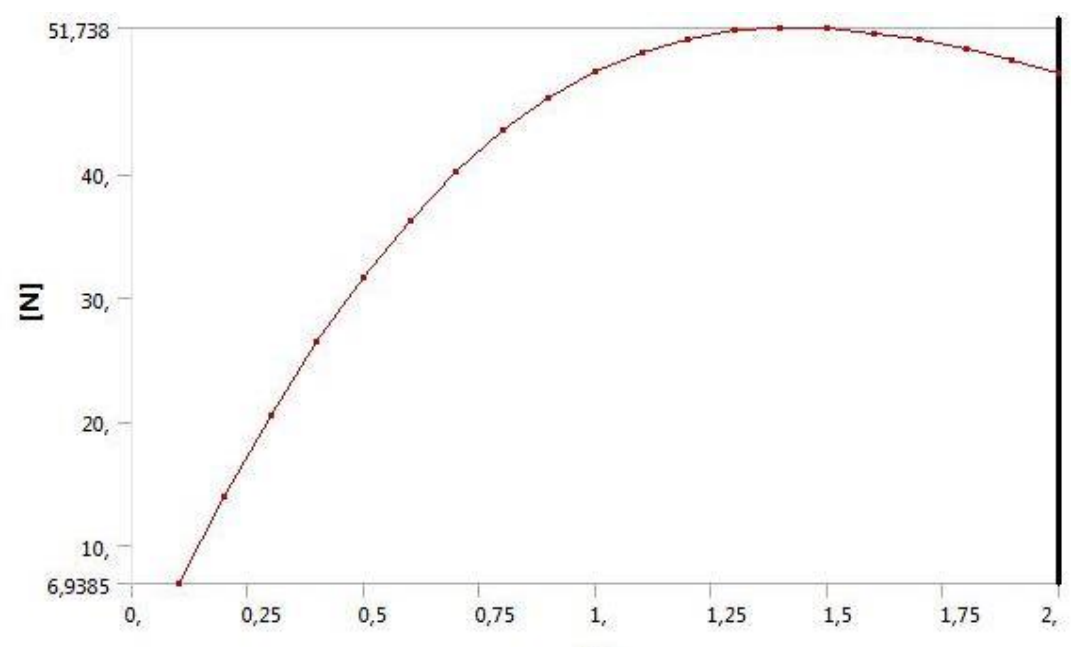

[s]

Fig. 5. Diagram force reaction vs. time

The accuracy of the results can be considered acceptable. It is observed that the results obtained from finite element analysis are very similar to the test results.

We can conclude that the proposed model simulate very well delamination defects within composite structures. There were obtained very close values for the results of force reaction in cases studied, experimental part and FEA simulation. The finite element analysis is confirmed by the test results. 


\section{Conclusions}

This paper presents the results obtained both by experimental research and finite element simulations. The manufacturing technologies used were hand lay-up process and compression hand lay-up process for the composite plates. In order to show the pressure influence on mechanical properties at delamination tests, the plates were compressed at $0,16 \mathrm{MPa}$ pressure. The used materials were unidirectional fabric $225 \mathrm{~g} / \mathrm{m}^{2}$ and polyester resin Lerpol TIX 3603/R.

The experiments consist in delamination tests, to find out the maximum value of the force when delamination occurs and the specific resistance at delamination. By compression hand lay-up process, a 38,54\% less force value at delamination was obtained than in the case of the simple hand lay-up process. In this case, we can conclude that the important role is played by the matrix, the force at delamination being taken by the resin.

This paper analyzed the delamination process at polymeric composite materials under transverse loads using the ANSYS 16.0 Software. The analysis proposed to determine the maximum force at delamination during transverse loads. We can observe that the results obtained from finite element analysis are very similar to the test results. The finite element analysis is confirmed by the test results and shows a good prediction of interlaminar failure.

\section{References}

1. E.E. Gdoutos, Fracture mechanics. An introduction. Second Edition (Springer, USA, 2005)

2. L.P. Kollar, G.S. Springer, Mechanics of Composite Structures (Cambridge University Press, Cambridge, 2003)

3. L.M. Kachanov, Delamination Buckling of Composite Materials (Library of Congress in Publication Data, Brookline, Massachusetts, USA, 1990)

4. A.V. Miron, N. Bâlc, A. Popan, C.S. Borzan, P. Bere, AJME. 11, 2 (2013)

5. D.V. Hutton, Fundamentals of finite element analysis (Elizabeth A. Jones Publishers, USA, 2004)

6. I. Pascariu, Finite element Concepts-Applications (Military Publisher, Bucharest, 1985)

7. O.O. Ochoa, J.N. Reddy, Finite element analysis of composite laminates (Kluwer Academic Publishers, USA, 1992)

8. D. Gay, J. Gambelin, Une aproche simple du calcul des structures par la methode des elements finis (Hermes, Paris, 1991)

9. B.V. Sankar, Comp. Struct, 38, 2, p. 239-246 (1991)

10. A.M. Elmarakbi, N. Hu, H. Fukunaga, Comp Sci Tech, 69, p. 2383-2391 (2009)

11. D. Aveiga, M.L. Ribeiro, Math Probl Eng (2018)

12. S. Huzni, Ilfan M., Sulaiman T., S. Fonna, M. Ridha, A.K. Arifin, IJAME, 7, p. 10231030 (2013)

13. G. Alfano, M.A. Crisfield, Int J Numer Meth En., 50, p. 1701-1736 (2001)

14. A.M. Girao Coelho, Arch Computat Methods Eng. 23, p. 363-388 (2016)

15. D. Soteropoulos, K.A. Fetfatsidis, J.A. Sherwood, SIMULIA Community Conference, Proceedings (2012)

16. ASTM Standard D 5528-01 (2007) 